A N N A L E S Annales de Bretagne et des Pays de l'Ouest

\title{
Le convoi de la mer breton (1372-1559) : une stratégie de mutualisation des risques?
}

The Breton sea convoy (1372-1559): a strategy of risk mutualisation?

\section{Alain Gallicé et Laurence Moal}

\section{(2) OpenEdition}

Édition électronique

URL : http://journals.openedition.org/abpo/2626

DOI : $10.4000 / a b p o .2626$

ISBN : 978-2-7535-2843-7

ISSN : 2108-6443

Éditeur

Presses universitaires de Rennes

Édition imprimée

Date de publication : 30 juin 2013

Pagination : 153-178

ISBN : 978-2-7535-2838-3

ISSN : 0399-0826

\section{Référence électronique}

Alain Gallicé et Laurence Moal, « Le convoi de la mer breton (1372-1559) : une stratégie de

mutualisation des risques? », Annales de Bretagne et des Pays de l'Ouest [En ligne], 120-2 | 2013, mis en ligne le 30 juin 2015, consulté le 02 mai 2019. URL : http://journals.openedition.org/abpo/2626 ; DOI : $10.4000 / a b p o .2626$ 


\title{
Le convoi de la mer breton (1372-1559): une stratégie de mutualisation des risques?
}

\author{
Alain GALLICÉ \\ Docteur en histoire médiévale \\ chercheur associé au CRHIA, EA 1163 - Université de Nantes \\ Laurence MOAL \\ Docteur en histoire médiévale \\ chercheuse associée au CERHIO, UMR 6258 CNRS - Université de Rennes 2
}

Étudier la mutualisation des risques inhérents aux activités maritimes en Bretagne pose un redoutable problème de sources. Les mentions, éparses, ne manquent pas mais il est impossible, par exemple, pour la parsonnie ${ }^{1}$, de faire état du moindre contrat portant sur un navire ou une cargaison, et encore moins de suivre un navire ou un parsonnier sur une certaine durée. Aussi, plutôt que de multiplier des allusions à des pratiques de mutualisation mieux établies par ailleurs, le parti a-t-il été pris de faire le point sur une autre stratégie, le « convoi de la mer".

Le $1^{\text {er }}$ juillet 1372, une ordonnance du duc Jean IV institue un convoi ${ }^{2}$, c'est-à-dire, dans une logique de sécurisation, la concentration de navires marchands escortés par des navires " de guerre " mobilisés à cet effet dans le cadre d'un système réglementé sur un trajet donné et à une date fixée. Cette création est à rapprocher d'un convoi flamand mentionné en

1. Par exemple, Arch. dép. de Loire-Atlantique, B 2986, $\mathrm{f}^{\circ} 223,230-231,242 \mathrm{v}^{\circ}$. Voir Touchard, Henri, Le Commerce maritime breton à la fin du Moyen Âge, Paris, Les Belles Lettres, 1967, p. 22, 368-369; et surtout BERNARD, Jacques, Navires et gens de mer à Bordeaux (vers 1400-vers 1550), 3 vol., Paris, SEPVEN, 1968, t. III, passim; ou encore Arch. dép. du Finistère, 1 E 727 ; Arch. dép. de Loire-Atlantique, B 10, f ${ }^{\circ}$ 237-248 vº 29-30 août 1487 ; B 26, f $211 \mathrm{v}^{\circ}, 7$ décembre 1521.

2. Mise au point récente : KERHERVÉ, Jean, L'État breton aux $14^{e}$ et $15^{e}$ siècles : les ducs, l'argent et les hommes, 2 vol. Paris, Maloine, 1987, t. II, p. 682-686; Id., " Le vin et l'impôt public en Bretagne aux $14^{\mathrm{e}}$ et $15^{\mathrm{e}}$ siècles ", dans Études sur la Bretagne et les pays celtiques, Mélanges offerts à Yves Le Gallo, Brest, CRBC, 1987, p. 190-193. 
$1371^{3}$, d'un autre, anglais, ordonné par Édouard III, le 14 octobre 1372, vers Bordeaux ${ }^{4}$, alors qu'un convoi hanséate vers la baie de Bourgneuf existe également. Dans les cas flamand et anglais, l'intervention des autorités cesse rapidement puisque les navires de ces pays peuvent naviguer alors de conserve, mais sans escorte de navires " de guerre " armés par celles-ci ${ }^{5}$, alors qu'en Bretagne le système établi en 1372 ne disparaît qu'au cours du $\mathrm{XVI}^{\mathrm{e}}$ siècle. L'originalité du convoi breton tient donc au fait qu'il ne répond pas seulement à un problème ponctuel d'insécurité mais qu'il est aussi une institution publique dans laquelle se mêlent, dès l'origine, des préoccupations politiques, économiques et fiscales ${ }^{6}$. En effet, si les frais sont en principe à la charge des marchands, l'équipement est décidé par le conseil ducal et financé par une taxation publique ${ }^{7}$. Il fait partie des droits royaux revendiqués par les ducs ${ }^{8}$, ce qui se traduit par la tradition d'ancienneté associée au convoi dont les Bretons font remonter la création à Conan Mériadec, le premier des rois légendaires de Bretagne ${ }^{9}$. D’autre part, le convoi breton survit au duché puisqu'il est ensuite très souvent renouvelé jusqu'en 1559, date de sa suppression définitive ${ }^{10}$.

Ce constat conduit à s'interroger sur la nature du convoi breton : peut-il être considéré comme une forme de mutualisation des risques? Ou est-il avant tout une institution publique? Si la réponse à ces questions a pu varier avec le temps, elle exige d'examiner les motivations de l'État breton, puis de l'État français après l'union du duché au royaume, mais aussi de s'interroger sur son efficacité et sur l'adaptation du convoi breton aux demandes exprimées par les marchands et les transporteurs : répond-il à leurs attentes? Comment réagissent-ils à un système imposé par le pouvoir

3. CRAEYBECK, Jan, Un grand commerce d'importation : les vins de France aux anciens

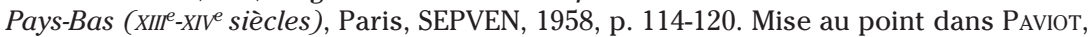
Jacques, La Politique navale des ducs de Bourgogne, 1384-1482, Lille, Presses universitaires de Lille, 1995, p. 201-205; Russon, Marc, Les Côtes guerrières : mer, guerre et pouvoirs au Moyen Âge, France-Façade océanique, XII⿸-XVe siècles, Rennes, PUR, 2004, p. 257-265.

4. DARSEL, Joachim, "La protection des flottes du vin au Moyen Âge dans la Manche et dans l'Atlantique ", Bulletin philologique et historique, Paris, éd. CTHS, p. 188-190.

5. Ibidem, p. 190; Jacques Paviot ne signale, pour la période 1384 à 1482, qu'à deux reprises (en 1387 et 1436) un projet du duc de Bourgogne d'armer un convoi de protection de la flotte gagnant La Rochelle, projet qui n'est réalisé qu'en 1387 (La Politique navale des ducs de Bourgogne..., op. cit., p. 205).

6. Il figure à ce titre dans Planiol, Marcel, Histoire des institutions de la Bretagne, 4 vol., Mayenne, éd. Floch, 1981-1982, t. IV, p. 61-63.

7. Arch. dép. de Loire-Atlantique, E 126/7. JonEs, Michael, Recueil des actes de Jean IV, duc de Bretagne, 2 vol., Paris, Klincksiek, 1980-1983, n 201.

8. KERHERVÉ, Jean, "Les enquêtes sur les droits "royaux et ducaux" de Bretagne aux XIV ${ }^{\mathrm{e}}$ et XV $\mathrm{X}^{\mathrm{e}}$ siècles ", dans Boudreau, Claire, FIANu, Kouky, Gauvard, Claude et HéBot, Michel, (dir.), Information et société en Occident à la fin du Moyen Âge, Actes du colloque international tenu à l'université du Québec à Montréal et à l'université d'Ottawa (9-11 mai 2002), Paris, Publications de la Sorbonne, 2004, p. 405-425.

9. $\mathrm{BnF}, 16735, \mathrm{f}^{\circ} 106$.

10. Et non 1555, comme il est énoncé traditionnellement à la suite de MoRICE, Hyacinthe, Mémoires pour servir de preuves à l'histoire ecclésiastique et civile de Bretagne, 3 vol., Paris, 1742-1746, t. III, col. 1123-1124. 
central? Sa mise en place n'a-t-elle pas bloqué l'émergence d'autres formes de mutualisation des risques, sous forme d'association ou de réseaux, voire d'assurance? Notre documentation, limitée et d'origine publique, permet d'apporter des éléments de réponses à certaines des questions posées. Après avoir présenté le convoi breton, nous nous interrogeons sur sa nature puis nous étudions les oppositions qu'il suscite et les conditions qui marquent sa suppression.

\section{Une organisation à géométrie variable}

\section{Périodicité, trajet et aspects du convoi}

L'état de la documentation ne permet pas d'établir un calendrier. Pour Marcel Planiol, le convoi se forme "à peu près tous les ans ${ }^{11}$ ". Cependant, parmi les registres conservés de la chancellerie bretonne, ceux de 1466, $1467,1468,1480$ et $1487^{12}$ ne contiennent pas de lettre de convoi; ils attestent une certaine irrégularité, d'autant que certains convois ordonnés peuvent être annulés, comme en 1406 et $1470^{13}$ (voir Annexe, figure 1)

Équipés, les navires escorteurs se placent à la pointe de Bretagne, au " chenal de Saint Mahé " (Saint-Mathieu) ou dans le passage du Four ${ }^{14}$ (figure 1). La concentration des navires marchands peut commencer, un ${ }^{15}$, parfois deux ${ }^{16}$, navire(s) escorteur(s) est (sont) dépêché(s) jusqu'à Bréhat ou Saint-Malo (en 1473) pour convoyer ceux de la côte nord. Puis, lors de son avance vers le sud-est, le convoi est rejoint par des navires en provenance des ports de Cornouaille, du Vannetais et du Pays nantais ${ }^{17}$. En 1503, une double concentration est signalée : pour ceux " de la le ras a Blavet " et ceux " deza a Morbihan ${ }^{18}$ ". La partie la plus importante du convoi gagne La Rochelle et certains navires d'escorte se placent " entre les terres ${ }^{19}$ " à l'abri des îles de Ré et d'Oléron; d'autres navires marchands poursuivent leur parcours vers Bordeaux ou Bayonne sous escorte réduite. Une nef et une barque gagnent Guérande et escortent les navires réunis " dans la riviere de Guerande ${ }^{20}$ ". Les cargaisons chargées, la flotte se reconstitue et

11. Planiol, Marcel, Histoire des institutions de la Bretagne..., op. cit., t. IV, p. 61.

12. Arch. dép. de Loire-Atlantique, B 4, 6, 8, 9 et 11.

13. Voir Infra.

14. Arch. dép. de Loire-Atlantique, B 10, f $\mathrm{f}^{111} \mathrm{v}^{\circ}-112,9$ janvier 1487.

15. Arch. dép. de Loire-Atlantique, $B 7, \mathrm{f}^{\circ} 120 \mathrm{v}^{\circ}-121$.

16. C'est le cas en 1464 (Arch. dép. de Loire-Atlantique, B 3, f $\mathrm{f}^{\circ} 98-98 \mathrm{v}^{\circ}, 3$ août 1464); et la possibilité est évoquée en 1487, un ou deux (Arch. dép. de Loire-Atlantique, B 10, $\left.\mathrm{f}^{\circ} 111 \mathrm{v}^{\circ}-112\right)$.

17. Morice, Hyacinthe, Mémoires..., op. cit., t. III, col. 1122.

18. Arch. dép. de Loire-Atlantique, B 14, f ${ }^{\circ} 121 \mathrm{v}^{\circ}, 22$ septembre 1503.

19. Pour Arthur de La Borderie, il faut entendre entre la côte de Bretagne et celle de Bayonne ("Le commerce et la féodalité en Bretagne ", Revue de Bretagne et de Vendée, 1859/2, p. 452); pour Jean Kerhervé, il faut comprendre l'espace entre les îles de Ré et d'Oléron (L'État breton aux $14^{e}$ et $15^{e}$ siècles..., op. cit., carte p. 685).

20. L'expression est curieuse. Ne faut-il pas plutôt lire " riviere de Loire ", expression qui désigne l'estuaire de la Loire, dont les navires se rassembleraient aux environs de Guérande? 
refait un trajet inverse de celui de l'aller ${ }^{21}$, rejointe par les navires en partance de l'estuaire de la Loire. Une "monstre " se fait au retour : en 1487, au retour de la deuxième flotte, elle est assurée par Thomas de Kerasret, prévôt des maréchaux ${ }^{22}$.

Sur ce tracé, les "flottes " du convoi se succèdent. Par exemple, le 31 août 1462, "la lettre de convoy ", qui s'adresse aux navires destinés à aller charger des cargaisons de vins " dans les parties de La Rochelle, Bordeaux, Bayonne ", indique les effectifs, la durée et le positionnement de ces " flottes" : 500 " combatans bien equipez en bons navires", du 15 septembre au 15 novembre; 400 , du $1^{\mathrm{er}}$ février au $1^{\mathrm{er}}$ avril, dont 140 " combatans " sont affectés à la "flote du navire de Saint-Malo et des autres havres jusques a Brehat "; 300, du $1^{\text {er }}$ mai au premier jour de juin ${ }^{23}$. Trois flottes sont levées pour, chacune, une durée de deux mois. Leurs effectifs décroissants se calquent sur l'évolution de l'importance du trafic du vin à partir de l'Aunis et de la Gascogne vers le nord. La coupure de l'hiver s'explique en raison des conditions difficiles de navigation. Celle de printemps est destinée à " permettre auxdits navires de guerre [de] s'apprester et rafraichir leur vitaille ${ }^{24}$ ".

\section{Des aménagements qui témoignent d'une certaine réactivité}

Ce cadre général peut connaître divers aménagements. Les dates des diverses flottes fluctuent en raison des données viticoles (la date des vendanges et l'importance de la production variant selon les années). La première flotte peut intervenir le $1^{\mathrm{er}}$ septembre en $1484^{25}$, le 5 septembre en $1503^{26}$, le 8 septembre en $1464^{27}$, le $1^{\text {er }}$ octobre en 1473 (et jusqu'à Noël) ${ }^{28}$ et 1490 (et jusqu'au $1^{\text {er }}$ décembre) ${ }^{29}$ ou le 15 octobre en 1481 et $1482^{30}$; la seconde, le 15 janvier $^{31}$; la troisième peut s'arrêter le 15 mai $^{32}$ ou se prolonger jusqu'au 15 juin $^{33}$. Le nombre de flottes peut être augmenté et être porté à quatre, ainsi en $1459^{34}$; ou au contraire se réduire à deux avec la disparition de celle d'hiver, comme on le constate en 1483 : à la première flotte, entre le $1^{\text {er }}$ septembre au 30 novembre, succède une seconde entre

21. Morice, Hyacinthe, Mémoires..., op. cit., t. III, col. 1122.

22. Ibidem, col. 536.

23. Arch. dép. de Loire-Atlantique, B 2, f 91.

24. Morice, Hyacinthe, Mémoires..., op. cit., t. III, col. 1122.

25. Arch. dép. de Loire-Atlantique, E 212/17.

26. Arch. dép. de Loire-Atlantique, B 14, $\mathrm{f}^{\circ} 107 \mathrm{v}^{\circ}$.

27. Arch. dép. de Loire-Atlantique, B 3, f ${ }^{\circ} 96,2$ août 1464.

28. Arch. dép. de Loire-Atlantique, B 7, $\mathrm{f}^{\circ} 120 \mathrm{v}^{\circ}, 2$ septembre 1473.

29. Arch. dép. de Loire-Atlantique, B $12, \mathrm{f}^{\circ} 185 \mathrm{v}^{\circ}, 27$ septembre 1490 et B $13, \mathrm{f}^{\circ} 4$, 8 octobre 1490. LA BORDERIE, Arthur de, "Choix de documents inédits sur le règne de la duchesse Anne en Bretagne, 1488-1491 ", Bulletin de la Société archéologique d'Ille-etVilaine, 6, 1868, p. 322-324.

30. Arch. dép. de Loire-Atlantique, E 212/15-16.

31. Morice, Hyacinthe, Mémoires..., op. cit., t. III, col. 1122.

32. Arch. dép. de Loire-Atlantique, B 13, f ${ }^{\circ} 4,8$ octobre 1490.

33. Morice, Hyacinthe, Mémoires..., op. cit., t. III, col. 1122.

34. Arch. dép. de Loire-Atlantique, E 131, f ${ }^{\circ} 24 \mathrm{v}^{\circ}, 10$ juillet 1459. 
$1^{\mathrm{er}}$ mars au 15 avril $^{35}$; ou encore en 1487 (15 janvier au 8 mars et la seconde du 17 avril au 31 mai $^{36}$ ); voire semble-t-il, à une seule comme en 1473 (du 15 septembre à Noël ${ }^{37}$ ). La présence en mer d'une flotte peut se réduire à six semaines, par exemple en $1481^{38}$ et ou $1503^{39}$.

Certains convois peuvent recevoir une mission élargie. Le 2 août 1464, il est évoqué des destinations vers l'Espagne et le Portugal ${ }^{40}$. Le 17 mars 1471, la protection s'étend à l'ensemble du trafic, pour répondre au danger qui menace des navires bretons et d'" ailleurs " qui ne sont pas avertis de la présence d'un " grant nombre de navires d'Angleterre ", alors qu'ils envisagent d'appareiller pour gagner la Normandie, la Picardie, la Flandre, la Hollande, la Zélande et " autres contrées ". Le duc ordonne au convoi d'escorter les navires bretons actuellement en "Poictou, en notre païs et ailleurs, aians entencion et vouloir de voaiger marchandamment es païs dessus nommez, et autres contrées du quartier du nort, que ilz ne passent oultre le raz Saint Mahé, pour faire les dits voiage ${ }^{41}$ ".

\section{Navires et effectifs d'escorte}

L'escorte peut rassembler un nombre et des effectifs de combattants plus ou moins importants selon les années (cf. Annexe). Les effectifs en combattants des huit premières flottes connues se situent entre 400 en 1473 , et 1890 combattants en 1503, trois d'entre elles recevant entre 500 et 555 combattants, une 650 (en 1464), une 800 (en 1459), et une autre encore 1000 (en 1490). Dans cinq cas, le nombre de navires d'escorte est indiqué; il oscille entre quatre en 1473 et dix-sept en 1503, les valeurs intermédiaires étant de cinq et sept (en 1483). Il n'y a qu'en 1483 que le tonnage total des navires d'escorte est signalé : 720 tonneaux. Ces chiffres soulignent le caractère exceptionnel de la levée de 1490-1491 (guerre d'indépendance) et surtout de 1503 (guerre avec l'Espagne).

Pour la deuxième flotte, les effectifs des combattants ne sont connus que dans cinq cas; ils se situent entre 400 (en 1463, 1464, et 1487) et 600 combattants (en 1490); en 1487, trois navires (total : $681 \mathrm{tx}$ ) sont mobilisés. La deuxième flotte du convoi de 1483-1484 est un cas particulier : si elle comporte moins de navires que la première (six contre sept), elle regroupe plus d'hommes (887 contre 720) embarqués sur des navires tous de fort tonnage (de 160 à 300 tx, 1390 tx pour l'ensemble de la flotte ${ }^{42}$ ). Pour la troisième flotte, pour les trois cas connus, on compte 300 (en 1463

35. Arch. dép. de Loire-Atlantique, E 212/17.

36. Arch. dép. de Loire-Atlantique, B 10, $\mathrm{f}^{\circ} 111 \mathrm{v}^{\circ}-112,9$ janvier 1487.

37. Arch. dép. de Loire-Atlantique, B 7, $120 \mathrm{v}^{\circ}-121 \mathrm{v}^{\circ}$.

38. Arch. dép. de Loire-Atlantique, E 202/15.

39. Arch. dép. de Loire-Atlantique, B 14, $\mathrm{f}^{\circ}$ 107-108, 24 août 1503.

40. Arch. dép. de Loire-Atlantique, B 3, $96 \mathrm{v}^{\circ}$.

41. Arch. dép. de Loire-Atlantique, E 217/21. LA NiCOLLĖRE-TEIJERO, « La marine bretonne aux XV et Xvl ${ }^{\mathrm{e}}$ siècles ", Revue historique de l'Ouest, 1886/1, p. 412-413.

42. Arch. dép. de Loire-Atlantique, E 212/17. 
et 1465) à 400 (en 1460) combattants. Pour la quatrième flotte de 1460, ce sont 150 combattants qui sont recensés. Ces variations annuelles de l'importance de l'escorte sont à mettre en relation avec l'importance du trafic attendu (et donc des récoltes), mais également avec la situation politique et les dangers liés à la guerre et à son cortège d'entreprises corsaires.

Concernant les navires ${ }^{43}$, l'information n'est donnée que dans sept cas, et de façon incomplète (cf. Annexe). Les nefs dominent (16 mentions), les caravelles (3) ne sont pas absentes, non plus que les barques (2); caraque et baleinier ne sont cités qu'une seule fois. Pour les tonnages, le plus fort est de 300 tx et le plus faible de 10 tx. Les flottes associent des types et des tonnages variés (une exception cependant en 1484). La nécessaire présence d'une unité au moins de fort tonnage est soulignée en 1465. Cette variété est gage de capacités manœuvrières : les grosses unités offrent une forte capacité de défense alors que les moyennes et petites sont plus mobiles. La diversité de l'origine géographique des navires d'escorte est à souligner. Pour l'époque ducale, nos rares informations (cf. Annexe) soulignent l'importance de la côte nord (Morlaix, Saint-Malo, Saint-Pol-de-Léon) et de Brest, sans exclure la côte sud (Auray, Le Croisic). Le convoi de 1503, faisant appel à un plus grand nombre de navires, ouvre le spectre géographique à l'ensemble des côtes bretonnes (Saint-Malo, Tréguier, Morlaix, Quimper, Vannes, Le Croisic), afin de mobiliser un plus grand nombre de bâtiments. Quant aux propriétaires des navires, à l'époque ducale, ce sont des officiers militaires (amiral et vice-amiral), des officiers de finance (en 1483, Jean Péro, Geoffroy Estrillart et le trésorier Pierre Landais) et des armateurs (par exemple, Derien Le Du en 1483) ${ }^{44}$. Le duc peut également engager ses propres bâtiments ${ }^{45}$. En 1503, les officiers n'apparaissent plus, les navires sont ceux de gens de mer tel Portzmoguer ${ }^{46}$.

Peut-on aller plus loin que cette vue impressionniste? Un Mémoire, non daté, trace une perspective générale. Il fait état d'" un grand renfort d'armée et des plus puissants navires du pays au nombre de dix ou douze, tant bonnes nefs que barques, esquipées d'environ mille cinq cens combatans, tant mariniers que autres gens de guerre "; mais parfois le nombre se limite à 800 ou 1000 hommes et 7 ou 8 navires, " sçavoir six nefs et deux barques ». Ce texte, qui a trait à la période ducale, pourrait dater de la fin du $\mathrm{XV}^{\mathrm{e}}$ siècle et être destiné à étayer une demande des marchands adressée au roi Charles VII à laquelle celui-ci répond en $1493^{47}$. S'il en est bien ainsi, il est

43. Sur les aspects de la flotte bretonne en 1487 : CASSARD, Jean-Christophe, « Des marins bretons au service du duc assiégé dans Nantes en 1487 ", Mémoires de la Société d'histoire et d'archéologie de Bretagne, 88, 2008, p. 99-110.

44. Arch. dép. de Loire-Atlantique, E 212/7.

45. Arch. dép. de Loire-Atlantique, E 212/15.

46. LA Borderie, Arthur de, "Hervé de Porzmorguer, documents inédits, 1503-1510", Bulletin de la Société archéologique du Finistère, 12, 1885, p. 7.

47. Morice, Hyacinthe, Mémoires..., op. cit., t. III, col.1121, le publie en regard d'un acte de 1555. LA BoRDERIE, Arthur de, "Le commerce et la féodalité en Bretagne ", Revue de Bretagne et de Vendée, 1859/2, p. 451, le situe à la fin du $\mathrm{XV}^{\mathrm{e}}$ siècle. 
à penser que le convoi est présenté dans ce Mémoire sous un jour favorable aux requérants, insistant sur la qualité des navires d'escorte fournis et une quantité d'unités jugée, par eux, la plus satisfaisante, sans entrer plus avant dans les détails, en particulier dans l'évolution des effectifs selon les flottes qui se succèdent dans l'année. Par rapport à nos informations, le nombre de navires est supérieur, alors que les effectifs exprimés en équipage (et non en combattants, on admet que ceux-ci sont de nombre relativement égal à celui des hommes d'équipage selon la règle du "double équipage ") sont plus en rapport.

\section{Une stratégie de mutualisation des risques marchands confisquée par le pouvoir politique}

Par certains de ces aspects, réponse à un péril, demande venant des marchands, réactivité pour sa mise en place, actions des navires d'escorte et efficacité de ceux-ci, le convoi breton peut apparaître une stratégie de sécurisation et de mutualisation des risques marchands.

\section{Officiellement, une réponse à un péril, à la demande des marchands eux-mêmes}

À sa création en 1372, le convoi est une réponse aux "pertes et granz dommages de lours marchandies " infligées "sur la mer " par "plussours de divers nations " à " noz sugiez et especial les marchanz mareanz sur mer ". Il s'adresse aux Bretons, " marchenz et autres ", mais également aux marchands étrangers venant commercer en Bretagne ${ }^{48}$. Cette volonté de défense se retrouve en novembre 1406, afin de faire face " aux pilleries et robries que font en sorte plusieurs escumeurs de mer $^{49}$ ». Par la suite, la menace est nommément désignée : elle est d'abord anglaise. La « lettre de convoy " du 31 août 1462, dénonce les Anglais " pirates de mer et autres ennemys " sur la route du vin vers l'Aunis et la Gascogne ${ }^{50}$, Anglais nommément désignés le $1^{\mathrm{er}}$ août $1464^{51}$, alors que, le 31 août 1470 , sont évoquées les " invasions, pilleries et destrousses " dont sont responsables la flotte de Warwick, " ses gens et adherez, que autres pirates de mer ${ }^{52}$ ". Le 17 mars 1471, il est encore fait état de la présence d'un " grant nombre de navires d'Angleterre, en entencion de prendre, piller et endommaiger ", qui exige de protéger les navires bretons et d'" ailleurs ${ }^{53}$ ». Le 2 septembre 1473,

48. Arch. dép. de Loire-Atlantique, E 126/7; JonEs, Michael, Recueil..., op. cit., n 201.

49. Blanchard, René, Lettres et mandements de Jean V, duc de Bretagne, de 1402 à 1442 , Nantes, Société des bibliophiles bretons et de l'histoire de Bretagne, 5 vol., 1889-1895, $\mathrm{n}^{\circ} 365$.

50. Arch. dép. de Loire-Atlantique, B 2, $\mathrm{f}^{\circ} 91$.

51. Arch. dép. de Loire-Atlantique, B $3, \mathrm{f}^{\circ} 96-96 \mathrm{v}^{\circ}$ et $97 \mathrm{v}^{\circ}$. Voir également $\mathrm{f}^{\circ} 86 \mathrm{v}^{\circ}$, 12 juillet 1464. Russon, Marc, Les Côtes guerrières..., op. cit., p. 260.

52. Arch. dép. de Loire-Atlantique, E 127/20.

53. Arch. dép. de Loire-Atlantique, E 217/21. LA Nicollière-TEIJERo, « La marine bretonne..." "op. cit., p. 412-413. 
le spectre de la menace s'élargit : aux " pirates, larrons et escumeurs de mer ", de Fowey et de Dartmouth (Angleterre), s'ajoutent ceux " des parties d'Espaigne et de Portugal que d'autres contrées ${ }^{54}$ ".

À la fin du xve siècle, la désignation géographique du danger n'apparaît plus. Le 9 janvier 1487, il est fait état de " pirates, larrons et escumeurs de mer " de " diverses nacions et autres ${ }^{55}$ ", alors que le 27 septembre 1490, sont dénoncés " noz ennemis et adversaires, aussi des pirates et escumeurs de mer ${ }^{56}$ ", puis le 8 décembre 1490, « les hostilitez des guerres », et la présence de " pluseurs gens de guerre, pirates et escumeurs [qui] se tiendront en flote et armée sur mer ${ }^{57}$ ". À ces dates, ces formules désignent le danger français lors de la guerre d'indépendance ${ }^{58}$. Le Mémoire, déjà cité et qui pourrait être lié à un acte de 1493, associe le convoi à la guerre " ouverte " avec les Anglais, à la sécurité de la navigation des flottes du vin et dans son fonctionnement ne fait écho qu'aux navires en provenance de ports bretons ${ }^{59}$. Le 25 août 1503 , l'inquiétude vient de la présence de la flotte espagnole ${ }^{60}$.

Officiellement, comme le rappelle un acte du 8 décembre 1490 de la chancellerie ducale, le convoi fait suite à une demande " de la part de plusieurs marchans de nostre pays et duché frequentans la mer ${ }^{61}$ ". En novembre 1493, Charles VIII s'engage à y répondre ${ }^{62}$. Le 25 août 1503, la demande émane des " bourgeoys et marchans " assemblés à Vannes, pour les États, qui s'inquiètent de la présence de la flotte espagnole alors que se profile " prochainnement la saeson des vendenges ${ }^{63}$ ".

Le convoi a-t-il répondu à ces attentes? En fait, la navigation et l'action des navires escorteurs restent une grande inconnue. Parmi les rares documents disponibles, citons une lettre de rémission du 3 avril 1531. Elle met en présence un navire et son équipage " tenant convoy aux marchans de Bretaigne pour aller seürement avec leurs marchandises sur mer de paour des ennemys ${ }^{64}$ " qui, " apres avoir esté par plusieurs jours sur mer a chassé les ennemys, se seroint trovez tous las et fatiguez et retirez à terre en en havre de la coste de Bretaigne entre les isles de Groy, de Nons [?] et de Bourg nouveau, pour eulx refrescher et avitailler lesdits navires ${ }^{65}$ ".

54. Arch. dép. de Loire-Atlantique, B 7, $\mathrm{f}^{\circ} 120 \mathrm{v}^{\circ}$.

55. Arch. dép. de Loire-Atlantique, $B 10, \mathrm{f}^{\circ} 111 \mathrm{v}^{\circ}$.

56. Arch. dép. de Loire-Atlantique, B 12, 27 septembre 1490, f $185 \mathrm{v}^{\circ}$. LA BORDERIE, Arthur de, "Choix de documents inédits sur le règne de la duchesse Anne... ", op. cit., p. 322-324.

57. Arch. dép. de Loire-Atlantique, B 13, f 4, 8 septembre 1490.

58. Le PAGE, Dominique et NASSIET, Michel, L'Union de la Bretagne à la France, Morlaix, Skol Vreizh, 2003, p. 86-103 (mise au point récente sur cette guerre dont les trois épisodes se déroulent entre 1487 et 1491).

59. Morice, Hyacinthe, Mémoires..., op. cit., t. III, col. 1121.

60. Arch. dép. de Loire-Atlantique, B 14, f ${ }^{\circ}$ 107-108.

61. Arch. dép. de Loire-Atlantique, B 13, f ${ }^{\circ} 4,8$ septembre 1490.

62. Morice, Hyacinthe, Mémoires..., op. cit., t. III, col. 746.

63. Arch. dép. de Loire-Atlantique, B 14, $\mathrm{f}^{\circ}$ 107-108.

64. Arch. dép. de Loire-Atlantique, B 33, $\mathrm{f}^{\circ} 53 \mathrm{v}^{\circ}$.

65 . Arch. dép. de Loire-Atlantique, $B 33, f^{\circ} 53 v^{\circ}-56 v^{\circ}$. Les faits sont antérieurs à la lettre de rémission de deux ans et demi. 
L'efficacité de telles actions de " chasse " ne peut être appréciée qu'indirectement. L'absence de documents concernant la capture d'une flotte entière (à l'image des flottes flamandes en 1371, 1387, ou flamande, zélandaise, hollandaise et hanséatique en $1449^{66}$ ), ou d'une partie de celle-ci, plaide pour l'efficacité du système ${ }^{67}$. La progression en convoi, la présence de navires d'escorte aux caractéristiques manœuvrières variées ont un incontestable caractère dissuasif. D'autre part, sur cette route du vin qu'emprunte le convoi, à une époque où le pavillon ne garantit pas la neutralité (ce qui ouvre le champ des menaces potentielles), les cargaisons embarquées par les navires rouliers bretons étant souvent, au moins en partie, possédés par des Anglais, celles-ci ne sont pas des cibles pour la marine anglaise, une des seules capables de s'emparer de telles flottes ${ }^{68}$. Il en va différemment lors des guerres avec la France (1490) et l'Espagne (1503), l'escorte est alors renforcée.

Toutefois, notre documentation, dont d'origine est publique, met en valeur un autre aspect du convoi : son caractère d'institution publique que ce soit par sa finalité, sa procédure de mise en place, son organisation, et sa fiscalité.

\section{Une institution politique de plus en plus contraignante pour les marchands}

\section{Une finalité : "le bien publicque »}

La lettre de convoi du 31 août 1462 rappelle le devoir du duc de " pourveoir à la garde, protection et deffence " de ses sujets, de préserver les marchands, leurs biens et leurs navires sur la route du vin vers l'Aunis et la Gascogne ${ }^{69}$. Le 25 août 1503, la puissance publique affirme assurer la sécurité alors que se profile "prochainnement la saeson des vendenges", période de navigation et d'échanges qui « tourne au bien universel ", à l'augmentation des " deniers " publics ${ }^{70}$ et plus largement au " bien publicque ${ }^{71}$ ", notion liée à l'exercice du pouvoir régalien. Ce discours se prolonge au-delà de la période ducale; en 1555, le roi Henri II déclare que la taxe de convoi est instituée pour " le bien, repos et tranquilité de ses sujets ", afin qu'ils puissent " librement faire et continuer leur trafic de marchandise sur mer " et de " conserver leurs biens et personnes sans tomber en l'oppression de nos ennemis ${ }^{72} "$.

La puissance publique peut viser encore d'autres objectifs. En effet, les navires escorteurs du convoi peuvent, le cas échéant, être affectés à

66. Paviot, Jacques, La Politique navale des ducs de Bourgogne..., op. cit., p. 201-205.

67. Russon, Marc, Les Côtes guerrières..., op. cit., p. 262.

68. Ibidem, p. 262.

69. Arch. dép. de Loire-Atlantique, B 2, f ${ }^{\circ} 91$.

70. Arch. dép. de Loire-Atlantique, B 14, $\mathrm{f}^{\circ}$ 107-108.

71. Arch. dép. de Loire-Atlantique, E 127/10, 31 août 1470.

72. MoRICE, Hyacinthe, Mémoires..., op. cit., t. III, col. 1123. 
des usages plus particuliers, d'ordre politique ou/et militaire. En 1483, des navires de la première flotte du convoi (5 sur 7) sont utilisés, pendant un mois, pour faire passer clandestinement en Angleterre les seigneurs de Richemont et de Pembroke. François II, ayant décidé de mettre une flottille à la disposition d'Henri Tudor, le " convoi de mer " est une couverture idéale $^{73}$. En novembre 1493, Charles VIII, en réponse aux marchands qui entendent que le convoi ne soit organisé qu'en cas de danger pesant sur la navigation, se réserve le droit de l'imposer en cas de « besoin et urgente necissité ", c'est-à-dire sans l'accord des marchands ${ }^{74}$ et sans doute dans une logique fiscale ou militaire. Le convoi apparaît alors pleinement comme une institution.

\section{Une procédure administrative}

Durant la période ducale, la procédure de mise en place du convoi est du ressort du conseil ducal. Un registre plumitif du conseil ducal fait état, le 29 juin 1459, de l'envoi par le duc de Maurice de La Noé et de Maurice de L'Isle « pour parler aux gens, marchans, mariniers frequentans la mer, touchant le convoy de la mer et leur dire et signiffier, de par le duc et son conseil, qu'ilz ne se departent de ceste ville de Vennes, jusques à en avoir ouy leurs opinions " et nomme pour "y besongner " plusieurs personnes, dont l'amiral et le chancelier ${ }^{75}$. Le 4 juillet 1459 , au conseil ducal (à l'ordre du jour duquel figure également la question de la paix avec le Portugal), s'expriment Colin Héron de Saint-Malo, Maurice de La Noé, Maurice de L'Isle, Alain Le Sandevez, Daniel de Saint-Alouarn, Guillaume Gousselin de Saint-Malo, Guillaume Baud de Quimper, Guillaume Le Breton, Paul Pinart, Guillaume du Quenquizou de Tréguier, Guillaume Rocquel de Saint-Brieuc, Olivier Avalleuc, Antoine de Bichaut de Saint-Brieuc, Jean de Cozcastel, Jean Geort, Goulven de La Boexière. Certains sont des gens de finances ${ }^{76}$, d'autres des marchands ${ }^{77}$. Le conseil ducal doit se prononcer sur la nécessité et les

73. Pocquet du Haut-Jussé, Barthélemy Anatole, François II duc de Bretagne et l'Angleterre (1458-1488), Paris, de Boccard, 1929, p. 249-250; la Marie d'Auray et le Léon restant affectés au convoi.

74. Morice, Hyacinthe, Mémoires..., op. cit., t. III, col. 746.

75. Arch. dép. de Loire-Atlantique, E 131, $\mathrm{f}^{\circ} 15$. Autre exemple de consultation, à une date inconnue, le duc convoque à Pontivy le sieur de Coitivy, chambellan, le sénéchal de Vannes et Jamet Thomas, bourgeois de Nantes, avec plusieurs personnes « a ce cognoessans " (Planiol, Marcel, Histoire des institutions..., op. cit., p. 61-62, note 22).

76. Maurice de La Noé, ancien trésorier, fermier des ports et des havres; Alain Le Sandevez, receveur de Concarneau, Daniel de Saint-Alouarn, ancien receveur de Quimper, Antoine de Bréhant, fermier des ports et havres d'entre le Couesnon et l'Arguenon, Goulven de La Boissière, fermier des ports et havres du Léon, Olivier Avalleuc fermier de l'impôt de l'évêché de Saint-Malo : KerHervé, Jean, Les Gens de finances des ducs de Bretagne, 1365-1491 : catalogue prosopographique, 3 vol. dactyl., Paris, 1986, passim.

77. Maurice de L'Isle de Morlaix, Guillaume Gosselin de Saint-Malo, Guillaume du Quenquizou de Tréguier, Guillaume Rocquel de Saint-Brieuc, Jean de Cozcastel, Jean Geort (KERHERvÉ, Jean, L'État breton aux $14^{e}$ et $15^{e}$ siècles..., op. cit., p. 682). 
modalités du convoi. S'exprimant le premier, Colin Héron préconise trois flottes, dont la première de la mi-septembre à la Saint-André; puis, Maurice de La Noé précise les effectifs - respectivement 800, 500 et 300 hommes -, et les dates : de mi-septembre à la Saint-André, févriermars, avril-mai. Pour l'avitaillement des navires d'escorte, des dépôts de vivres sont envisagés : "A Saint-Malo, Brehat, Treguier, Leon [...] y aura vitaille de biscuit et de chairs ${ }^{78}$. " La discussion se conclut par " touz disent que le convoi n'y pourroit suffire ", et aucune décision n'est arrêtée ${ }^{79}$. La question est reprise le 10 juillet 1459, en présence de l'amiral, du chancelier, du " grant maistre ", du procureur général, du trésorier général, de Villebranche, Labbé, Le Feron, des maîtres des requêtes, du sénéchal d'Hennebont et d'" autres". Il est alors décidé la constitution de quatre "flottes", de leurs dates, et de leurs effectifs ${ }^{80}$.

Il faut attendre 1462 pour disposer d'une documentation permettant d'appréhender la mise en place opérationnelle du convoi. Les décisions nécessaires sont enregistrées en chancellerie. Le 23 août, une mesure préalable est prise : elle fait défense " aux subgiz du duc frequentants sur mer de non mareer ne se metre sur mer pour faire voyage en quelque contrée que ce soit jucques quinzieme jour de septembre ${ }^{81}$ ". Puis, le 31 août, est publiée " la lettre de convoy " qui rappelle l'interdiction précédente, indique les effectifs, la durée, le positionnement de la " flote ${ }^{82}$ " et les obligations que le convoi implique. Pendant la durée du convoi, les navires marchands viticoles bretons doivent naviguer sous la protection des navires d'escorte; les contrevenants s'exposent à être " reputez rebelles et desobeissants " et à la " confiscation de leurs navires biens et marchandises dedans estans ${ }^{83}$ ".

Pour l'escorte, les navires requis peuvent être désignés dans la lettre de convoi, comme c'est le cas en $1503^{84}$. Figurent alors leur nom, leur propriétaire, leur tonnage, le nombre de combattants qui est à leur bord, le nom du capitaine et du maître de navire. Une " monstre " des navires et des " gens de guerre " précède l'embarquement. Elle est faite par des commissaires désignés par le duc : en 1457, ce sont Henri de Saint-Noan et Yvon de Tréanna ${ }^{85}$; le 22 septembre 1490 , le seigneur de Keinmarch, le chambellan

78. Arch. dép. de Loire-Atlantique, E 131, $\mathrm{f}^{\circ} 18 \mathrm{v}^{\circ}$.

79. Arch. dép. de Loire-Atlantique, E 131, $\mathrm{f}^{\circ} 18-18 \mathrm{v}^{\circ}$.

80. Arch. dép. de Loire-Atlantique, E $131, \mathrm{f}^{\circ} 24 \mathrm{v}^{\circ}, 10$ juillet 1459 ; indiqué pour le 10 juillet 1469 par LA NiCOLLIÈRE-TEIJERO, " La marine bretonne... ", op. cit., p. 413.

81. Arch. dép. de Loire-Atlantique, B 2, f 90 . Morice, Hyacinthe, Mémoires..., op. cit., t. III, col. 1122 .

82. Arch. dép. de Loire-Atlantique, B $2, \mathrm{f}^{\circ} 91$.

83. Arch. dép. de Loire-Atlantique, B 2, f $91 \mathrm{v}^{\circ}$-92. Morice, Hyacinthe, Mémoires..., op. cit., t. III, col. 1122. Sur cet officier militaire, JonES, Michael, "L'amirauté et la défense des côtes à la fin du Moyen Âge ", dans Bors, Jean-Pierre (dir.), Défense des côtes et cartographie historique, Actes du 124 $4^{\mathrm{e}}$ Congrès des Sociétés historiques et scientifiques, Nantes, 19-26 avril 1999, Paris, éd. du CTHS, 2002, p. 17-32.

84. Arch. dép. de Loire-Atlantique, B 14, f ${ }^{\circ}$ 107-108, 25 août 1503.

85. Morice, Hyacinthe, Mémoires..., op. cit., t. II, col. 1717. 
et capitaine de Quimper, Jean du Bouyer, sénéchal de Cornouaille, Jean du Bouyer le jeune, alloué d'Hennebont, Pierre Rouxelin, procureur d'Auray, ou deux d'entre eux ${ }^{86}$. Un capitaine est désigné pour chaque navire, " homme de bien congnoissant au fait de la mer, et par-dessus les autres capitaines un capitaine general, quel estoit grand personnage, craint et douté sur tous les autres capitaines ${ }^{87}$ ". En 1503, ce capitaine est Tanguy Madeuc ${ }^{88}$. Les navires escorteurs sont avitaillés et reçoivent de l'armement : en 1459, des dépôts de vivres sont prévus ${ }^{89}$; le 22 septembre 1503 , il est demandé au capitaine de Morlaix de fournir des " poudres de canon, hallebardes et picques qui sont audit Morlaix, jucques au nombre qu'ils verront suffire $^{90}$ ", alors que mandement est donné aux fermiers du devoir de convoi de fournir les vivres nécessaires et aux juges de Lamballe et Moncontour de prendre l'artillerie de feu Jean de La Chapelle " et autres " avec une " autre grosse pièce d'artillerie ${ }^{91}$ ». L'application de l'ensemble des mesures prises est confiée à l'amiral ${ }^{92}$.

\section{La fiscalisation de l'institution}

Selon le principe "puisqu'ils prennent prouffilt doivent en la charge ${ }^{93}$ ", les marchands contribuent à la dépense du convoi. En 1372, ils sont soumis à une taxe levée au cours de l'année dans chaque port sur des marchandises vendues, s'élevant, aux entrées, à 20 sous sur chaque tonneau de vin vendu provenant " de autre païs " mais à 10 sous si le vin est issu de Bretagne; aux sorties, à 8 sous par tonneau de "blé ", 12 sous par tonneau " de char " ou de " sueff ", 20 sous par tonneau " de quier de miele et de oint ", 10 sous par " cont de coue ", et 4 sous par " mue de sel ${ }^{94}$ " (voir Annexe, figure 2).

Ensuite, la liste des produits taxés se réduit. En 1384-1386, dans un compte tenu par le receveur ordinaire de Guérande figure une récapitulation du " minu de certain subside ordrenné par mondit seignour le duc pour le fet de la mer » dont le montant est d'un franc à l'entrée de chaque tonneau de vin de " hors " et 5 sous pour l'issue de chaque tonneau de

86. Arch. dép. de Loire-Atlantique, B 13, f ${ }^{\circ} 5,8$ octobre 1490. LA BordERIE, Arthur de, "Choix de documents inédits sur le règne de la duchesse Anne... ", op. cit., p. 320-321.

87. Morice, Hyacinthe, Mémoires..., op. cit., t. III, Col. 1123.

88. Arch. dép. de Loire-Atlantique, B 14, $121 \mathrm{v}^{\circ}$, 22 septembre 1503.

89. Voir Supra.

90. Arch. dép. de Loire-Atlantique, B 14, f $118 \mathrm{v}^{\circ}, 19$ septembre 1503.

91. Arch. dép. de Loire-Atlantique, B 14, $121 \mathrm{v}^{\circ}, 22$ septembre 1503.

92. Arch. dép. de Loire-Atlantique, B 2, f 91 v -92 .; Morice, Hyacinthe, Mémoires..., op. cit., t. III, Col. 1122. Sur cet officier militaire, JONES, Michael, "L'amirauté et la défense des côtes..." " op. cit., p. 17-32.

93. Arch. dép. de Loire-Atlantique, E 202/5.

94. Arch. dép. de Loire-Atlantique, E 126/7. JonEs, Michael, Recueil..., op. cit., n 201. Vicomte de Blois, "Le Président de Boisbilly et les exactions commises par les fermiers et receveurs des droits de ports et havres en Bretagne ", Bulletin de la Société archéologique du Finistère, 17, 1890, p. 194. 
froment ${ }^{95}$. En 1406, il est encore taxé « certaines especes de marchandies pour entrée et issue, pour durer jusques à ung $\mathrm{an}^{96}$ ".

$\mathrm{Au} \mathrm{XV}^{\mathrm{e}}$ siècle, levé à l'issue du convoiement, le prélèvement, dont le montant et l'assiette ont pu varier, concerne les vins quelle qu'en soit la provenance, transportés par voie maritime pendant la période qui s'ouvre avec la mise en place du convoi et se clôt avec la fin de celui-ci. En 1459 et 1462 , il représente le $20^{\mathrm{e}}$ des vins venant de Bordeaux, de Bayonne, de La Rochelle ou d'Anjou débarqués en Bretagne, mais le $40^{\mathrm{e}}$ de ceux venant de la zone située entre la " rivière de Loire " et le Morbihan, ainsi que sur les " vins mareyés hors Bretaigne durant le convoy ${ }^{97}$ ". En 1464, une exemption porte sur les vins venant " de la rivière de Loire ou havre de Morbihan et es autres havres entre Loyre et Morbihan ${ }^{98}$ ", exemption confirmée en $1473^{99}$.

En 1487, ce système laisse la place à une imposition uniforme de 10 sous par tonneau de vin importé en Bretagne venant des " parties de La Rochelle, Bordeaux, Bayonne et la riviere de Loire descendans" - l'exemption concernant les vins venant « de la riviere de Loire ou havre de Morbihan et es autres havres d'entre Loire et Morbihan " étant maintenue -, et de 5 sous par tonneau pour les vins descendus en " riviere de Loire ", de même que pour ceux déchargés dans les ports de la baie de Bourgneuf en provenance de la mer et " hors des isles " (alors qu'il y a exemption pour les cargaisons ne transitant pas par la haute mer mais entre les îles et le continent, c'est-à-dire lorsqu'elle n'avait pas recours au convoi) et encore sur ceux non destinés au duché ${ }^{100}$. Des exemptions personnelles peuvent être accordées, ainsi le 2 janvier 1461 à l'amiral pour 62 pipes et demie de vin de "Gascoigne ${ }^{101}$ ".

En 1490, on revient à une imposition au prorata du prix du vin montant au $20^{\mathrm{e}}$ des vins venant des " parties de La Rochelle, Bordeaux, Bayonne et aultres parties accoustumée " descendus en Bretagne " dela [ou oultre] le havre du Morbihan ", et au 40 e sur " ceulx qui viendront par la riviere de Loyre jusques audit havre, [et autres havres d'entre Loire et Morbihan] aussi qui seront tirés et menez hors " du duché ${ }^{102}$. À cette date, les expéditions de vin entre l'estuaire de la Loire et le golfe du Morbihan sont soumises au droit de convoi. Si la situation politique (guerre d'indépendance) a pu jouer pour expliquer une telle taxation sur une navigation de proxi-

95. Arch. dép. de Loire-Atlantique, B 2964. Ce compte révèle une flotte d'automne (les trois navires guérandais enregistrés le sont le 8 novembre 1384, un navire vannetais l'étant le 18), et une autre de printemps (avril-mai 1385).

96. BlanchaRD, René, Lettres et mandements..., op. cit., $\mathrm{n}^{\circ} 365$.

97. Arch. dép. de Loire-Atlantique, E 131, f ${ }^{\circ} 24 \mathrm{v}^{\circ}$, 10 juillet 1459 ; ibid., B 2, f $92-92 \mathrm{v}^{\circ}$.

98. Arch. dép. de Loire-Atlantique, B 3, 98 v, 3 août 1464.

99. Arch. dép. de Loire-Atlantique, B 7, $\mathrm{f}^{\circ} 121$.

100. Arch. dép. de Loire-Atlantique, B 10, $\mathrm{f}^{\circ} 111 \mathrm{v}^{\circ}-112$.

101. Arch. dép. de Loire-Atlantique, E 131, $\mathrm{f}^{\circ} 117 \mathrm{v}^{\circ}$.

102. Arch. dép. de Loire-Atlantique, B $12, \mathrm{f}^{\circ} 185 \mathrm{v}^{\circ}, 7$ septembre 1490 ; ibid., B $13, \mathrm{f}^{\circ} 4 \mathrm{v}^{\circ}$, 8 octobre 1490 . 
mité, elle est aussi, et surtout, l'expression d'une logique fiscale : la taxe du convoi porte alors sur l'ensemble du trafic maritime du vin ${ }^{103}$.

Les sommes réunies n'étant pas toujours suffisantes, le budget ducal est sollicité : 2500 livres en $1459^{104} ; 1500$ livres en $1462^{105} ; 2000$ livres en $1464^{106}$; en février 1487 , à propos du convoi ordonné "nagueres ", 3900 livres $^{107}$. Il n'y a pas de subvention mentionnée en $1487^{108}$, ni en $1490^{109}$. Selon le Mémoire, déjà évoqué, la possible participation du budget est de l'ordre de 5 sous sur l'ensemble des feux fiscaux du duché, ou le versement d'une somme de 3000 à 4000 livres provenant des « fouages, havres ou impostz ${ }^{110}$ ".

Le devoir de convoi est d'abord levé par les officiers ducaux de l'amirauté ou éventuellement de la trésorerie générale. Puis, à partir de 1481, il est baillé à ferme, autre signe tangible de la fiscalisation du droit de convoi. En 1481-1482, il est adjugé 9625 livres (pour un coût réel de 6450 livres); en 1482-1483, 15200 livres (pour 7000 livres), 1483-1484, 10250 livres. Lors de ce dernier exercice, une partie de l'argent obtenu aide à la construction de deux nefs et l'entretien de leur personnel ${ }^{111}$. En 1490, "l'outreplus " de la ferme du devoir de convoi est affecté à l'amiral ${ }^{112}$. La fiscalité liée au convoi a une finalité, plus large, de politique navale, dont on peut penser qu'elle est, au moins en partie, utile au convoi.

En janvier 1555, il est fait état d'une fiscalité nouvelle consistant en une taxe de 20 sous tournois sur chaque tonneau de marchandise, sans que l'on puisse préciser la date de cette nouvelle imposition, sinon qu'elle paraît dater du règne d'Henri II ${ }^{113}$. Finalement, détourné de sa fonction première, celle de répondre à un péril, le convoi est devenu une charge fiscale supplémentaire, mal supportée par les marchands car soumise à une forte réglementation, qui entrave le commerce plus qu'il ne le protège, surtout après la fin de la guerre avec la France en 1491. Malgré les réactions et les oppositions, la royauté le conserve encore plus d'un demi-siècle.

103. KERHERVÉ, Jean, L'État breton aux $14^{e}$ et $15^{e}$ siècles..., op. cit., p. 686.

104. Arch. dép. de Loire-Atlantique, $\mathrm{E} 131, \mathrm{f}^{\circ} 18 \mathrm{v}^{\circ}$.

105. Arch. dép. de Loire-Atlantique, $B 2, \mathrm{f}^{\circ} 91 \mathrm{v}^{\circ}$.

106. Arch. dép. de Loire-Atlantique, $B 3, \mathrm{f}^{\circ} 99$.

107. Morice, Hyacinthe, Mémoires..., op. cit., t. III, col. 535.

108. Arch. dép. de Loire-Atlantique, B $10, \mathrm{f}^{\circ} 111 \mathrm{v}^{\circ}-112$.

109. Arch. dép. de Loire-Atlantique, B $13, \mathrm{f}^{\circ} 4 \mathrm{v}^{\circ}, 8$ octobre 1490.

110. MoRICE, Hyacinthe, Mémoires..., op. cit., t. III, col. 1122.

111. Arch. dép. de Loire-Atlantique, E 212/15-17. KeRHERVÉ, Jean, L'État breton aux $14^{e}$ et $15^{e}$ siècles..., op. cit., p. 684 .

112. Arch. dép. de Loire-Atlantique, B $13, \mathrm{f}^{\circ} 7 \mathrm{v}-8$.

113. Morice, Hyacinthe, Mémoires..., op. cit., t. III, col. 1123. 


\section{Les oppositions au convoi et sa suppression}

\section{Les oppositions à l'institution}

Les documents sont comptés et surtout de source publique, c'est-à-dire filtrés et interprétés. Ils font état de réticences à la mobilisation des navires de l'escorte, navires marchands en temps ordinaire " retenus " pour la durée d'une des flottes du convoi. Le 8 octobre 1490, l'ordre de constitution du convoi est renouvelé ${ }^{114}$. Le 28 septembre 1503, quatre mandements sont pris " affin de contraindre incontinent se equipper et se mectre sur mer allencontre des Espaigneulx ", sauf peine d'arrestation ${ }^{115}$. La promesse faite que les capitaines et compagnons " joyront [...] des prinses et conquestes qu'ilz feront sur les navires qu'ilz pourront avoir et explecter dessur les ennemys ad ce qu'ilz aint meilleur couraige de deffendre le pays ${ }^{116}$ " pourrait être un argument pour favoriser les enrôlements. Ces réticences pourraient être une réaction à la contrainte imposée, voire aux rémunérations proposées. Dans l'état annuel de finances commencé le $1^{\mathrm{er}}$ octobre 1481, il est fait état de 4 livres par mois par homme et pour le navire de 10 sous par tonneau de fret par mois ${ }^{117}$; celui commencé le $1^{\text {er }}$ octobre 1483 est plus complet : 4 livres par homme et par jour, 10 livres pour le maître et le capitaine (plus les 4 livres pour combattants), 6 livres pour le contremaître, et pour le fret du navire 10 sous par tonneau et par mois ${ }^{118}$; chiffres que l'on retrouve le 22 février $1487^{119}$. Un Mémoire, non daté et déjà cité, qui pourrait être de la fin du XV siècle, fait état, " communs ans ", de 30 sous pour " vitaille", 40 sous de solde par homme et 10 sous par tonneau de fret à chaque navire par mois ${ }^{120}$.

Le volet fiscal est mal supporté : le 13 avril 1464, l'amiral obtient " executoire [...] sur ceux qui seront debiteurs audit amiral du devoir de convoy des sommes deues à celle cause "; en cas d'opposition, ajournement est prévu devant le duc et son conseil ${ }^{121}$. La fraude est pratiquée : le 5 février 1491, Éonnet du Bollan et ses " consors fermiers " du devoir de convoi obtiennent que les officiers de justice de Vannes, Cornouaille, Auray, Hennebont et Quimper enquêtent sur les marchands qui ont débarqué des vins sans le notifier aux fermiers ${ }^{122}$. À une date inconnue, mais vers la fin de la période ducale, l'amiral se plaint du refus de Thomas Le Roy et d'autres marchands de Nantes de payer " le devoir de convoi " prétextant une exemption portant sur l'ensemble des vins, et non uniquement sur

114. Arch. dép. de Loire-Atlantique, $B 13, \mathrm{f}^{\circ} 7 \mathrm{v}{ }^{\circ}-8$.

115. Arch. dép. de Loire-Atlantique, B 14, f ${ }^{\circ}$ 128, 28 septembre 1503.

116. Arch. dép. de Loire-Atlantique, B 14, f ${ }^{\circ}$ 107-108.

117. Arch. dép. de Loire-Atlantique, E $212 / 15, \mathrm{f}^{\circ} 24-25 \mathrm{v}^{\circ}$.

118. Arch. dép. de Loire-Atlantique, E 212/18, $\mathrm{f}^{\circ} 18-18 \mathrm{v}^{\circ}$.

119. Morice, Hyacinthe, Mémoires..., op. cit., t. III, col. 535.

120. Ibidem, col. 1123.

121. Arch. dép. de Loire-Atlantique, B 3, $\mathrm{f}^{\circ} 45$.

122. Arch. dép. de Loire-Atlantique, B 13, $\mathrm{f}^{\circ} 112$. 
certains d'entre eux ${ }^{123}$. En 1493, les États entendent que le devoir de convoi ne soit qu'un simple impôt ${ }^{124}$.

C'est en fait tout le dispositif qui paraît susciter des oppositions de la part des marchands et des transporteurs. À cet égard, deux mandements émanant de la chancellerie ducale peuvent être invoqués bien qu'ils constituent une source limitée et difficile à interpréter en raison de son laconisme. Le 27 février 1462, Guillaume Clenzière, maître d'une pinasse de Penmarc'h, Guillaume Le Corre, contremaître d'une escaffe d'Audierne, et Henri Pochin, maître d'une caravelle de La Forêt-Fouesnant, rapportent qu'ils ont gagné La Rochelle " puix Noel derroin ". Après avoir chargé une cargaison de vin, sur le chemin du retour, ils trouvent trois navires du Croisic affectés au convoi dont les maîtres (Guillaume Boulet, Jean Lespeau et Jacob Josses) s'engagent à les mener " jusques à certaines metes en la mer ". Les basBretons paient alors " des vins [...] pour ledit devoir ", se placent sous la protection du convoi, et... poursuivent tout bonnement leur route hors convoi. Or, le lendemain, ces trois navires marchands sont pris par un baleinier anglais, avant, qu' " une heure " après, ils ne soient délivrés par trois autres navires du Croisic qui les conduisent à l'Île d'Yeu où se trouvent les trois navires croisicais du convoi qui les mènent au Croisic, sans que l'on puisse savoir s'ils sont considérés de bonne prise (puisque pris sur les Anglais) ou confisqués pour ne pas avoir suivi la réglementation ${ }^{125}$. Le 31 mars 1462, le duc enjoint que soient rendus navires et marchandises aux bas-Bretons. On ignore les attendus de cette décision qui ne sanctionne les fautes ni des uns, ni des autres ${ }^{126}$ : les bas-Bretons n'ont pas respecté les obligations du convoi, ni à l'aller, ni au retour; les Croisicais n'ont pas confisqué les navires, ont levé (à leur avantage?) la taxe qui aurait due ne l'être qu'à l'issue du convoiement et n'ont pas tenu leur engagement de protection. Toujours est-il qu'en août 1462, le duc précise que la taxe de convoi ne peut être levée " jusques à ce que les vexeaux et vins soint descendus ou arrivez en seürté en noz portz et havres ${ }^{127}$ ". Dans ce cas, la navigation marchande s'est engagée hors du convoi, avec, sans doute, l'espoir de ne pas être soumis à la fiscalité du convoi, puis, contrôlés à leur retour, les navires poursuivent leur route. La prise de risque que représente l'absence de la protection du convoi pour ces navires se justifie par l'espoir de vendre une cargaison sur un marché que l'arrivée des navires du convoi ne sature pas. Chez certains marchands et transporteurs, la logique économique l'emporte; cette logique s'oppose aux contraintes qu'impose le convoi : calendrier imposé, incidences sur le marché du vin et fiscalité.

Ces oppositions ont pu conduire à l'annulation d'une décision de mise en œuvre du convoi. En novembre 1406, elle l'est sur la " remonstrance " de

123. Arch. dép. de Loire-Atlantique, E 202/5.

124. Morice, Hyacinthe, Mémoires..., t. III, col. 746.

125. Arch. dép. de Loire-Atlantique, B 2, $\mathrm{f}^{\circ} 16 \mathrm{v}^{\circ}$.

126. Arch. dép. de Loire-Atlantique, B 2, $\mathrm{f}^{\circ} 31-31 \mathrm{v}^{\circ}$.

127. Arch. dép. de Loire-Atlantique, B 2, 92, 31 août 1462. 
l'évêque de Nantes ${ }^{128}$. On ignore le contenu de cette "remonstrance ", mais il est tentant de rapprocher cette annulation du convoi de l'ordre donné à l'amiral Jean de Penhoët d'armer une flotte destinée à aller à Bordeaux au secours du roi de France, financée sur les revenus des ports et havres ${ }^{129}$ : dans un premier temps, le duc aurait été tenté de détourner le convoi à des fins militaires. En 1470, le convoi est également annulé, mais pour une autre raison : il l'est à la demande des marchands dont il entravait les opérations commerciales ${ }^{130}$. Cependant, pour les milieux marchands, jusque dans les années 1550, le principe même du convoi n'est pas remis en cause, mais il ne peut se justifier qu'à certaines conditions bien précises. En réponse à leur demande, en novembre 1493, Charles VIII s'engage à ne le mettre en place qu'en cas de "guerre et non seur accès d'aller par mer ", tout se réservant le cas d'imposer le convoi en "besoin et urgente necissité ${ }^{131}$ ". Pour les milieux marchands, il a une utilité : permettre le trafic du vin en temps de guerre.

La fin de l'indépendance bretonne ne signifie pas la fin du convoi. Notre documentation ne permet pas de corréler le convoi, et ses possibles évolutions, avec les étapes du dispositif d'intégration du duché au royaume ${ }^{132}$. Soulignons, cependant, quelques éléments. D'abord, l'attention portée par le pouvoir aux demandes émanant des milieux engagés dans le commerce, ce qui le conduit à rapporter des projets de taxation sur le sel (exemple, en 1499-1500 ${ }^{133}$ ) ou à des mesures d'interdiction d'exporter des céréales et parfois d'autres produits comme en septembre $1519^{134}$. D'autre part, lorsque le roi fait appel à l'aide maritime des Bretons, il se présente comme étant agressé par des ennemis du royaume (Espagne, Angleterre) et soucieux d'assurer la défense de la Bretagne. Plus profondément, dans un premier temps, le pouvoir royal intègre la marine (hommes, navires, chantiers navals) de la péninsule à ses objectifs et n'est pas hostile aux anciennes institutions bretonnes ${ }^{135}$. Cependant, dans le courant des années 1550, l'utilité même du convoi est discutée.

128. BlanchaRD, René, Lettres et mandements..., op. cit., n 365 et 372.

129. Ibidem, $\mathrm{n}^{\circ} 378$.

130. BnF, Clairambault $825, \mathrm{f}^{\circ} 101$, cité par DARSEL, Joachim, « La protection des flottes du vin au Moyen Âge... ", op. cit., n², p. 194.

131. Morice, Hyacinthe, Mémoires..., op. cit., t. III, col. 746.

132. Le PAGe, Dominique, Finances et politique en Bretagne au début des temps modernes au début des Temps modernes : étude d'un processus d'intégration au royaume de France, Paris, Comité pour l'histoire économique de la France, 1997; et sous une forme plus synthétique, LE PAGE, Dominique et NASSIET, Michel, L'Union de la Bretagne à la France..., op. cit. 133. Arch. dép. de Loire-Atlantique, E 129/28, proposition d'une taxe nouvelle de 5 sous tournois par pipe de sel exporté de Bretagne, Poitou et Saintonge.

134. Archives municipales de Nantes, HH 196, 11 septembre 1514, report des mesures prises le 9 août interdisant l'exportation des blés, sels et vins à partir de la Bretagne.

135. CASSARD, Jean-Christophe, "Frontière de mer et marine ducale : l'exemple breton, fin du XV et début XVI ${ }^{\mathrm{e}}$ siècle ", dans BoIs, Jean-Pierre (dir.), Défense des côtes et cartographie historique..., op. cit., p. 33-51, sur le rôle de la marine dans l'intégration du duché au royaume, p. $40-49$. 


\section{La dénonciation de la taxe et sa suppression en 1559}

Le 25 septembre 1554, lors de la réunion des États de Bretagne, une des remontrances adressées au roi concerne le convoi : "Que le droit de 20 sous par tonneau ne puisse être exigé des marchands qui ne sont nullement convoyés et obligés de se défendre eux-mêmes. " Le 17 janvier 1555, en réponse, le conseil du roi fait savoir que « le roi veut entendre l'affaire plus amplement pour y mettre une résolution que l'on pourra garder à l'avenir. En attendant, que les habitants se gouvernent comme par le passé et organisent quelque sûreté pour les marchands ${ }^{136}$ ".

En Bretagne, la taxe est dénoncée comme « de grande foule, charge et oppression ". Auprès du roi, Arthur Le Forbeur, le procureur des États, fait " amplement entendre l'incommodité, préjudice et dommage » d'une telle taxe. Il se fait l'écho des fermiers qui exposent les risques qu'elle fait peser sur le commerce et leurs ressources : les marchands, qui sont " accoustumé faire leurdit trafic audit païs, délaissent et abandonnent chacun jour leurs négociations "; la " force et la richesse d'icelui païs " s'en trouvent menacées. À court terme, il est à attendre que les navires "soient contrains de périr et pourrir es ports ", et le paiement des fermes ne pourrait plus être assuré. Au-delà du côté convenu et excessif de cet exposé, la réalité fiscale apparaît crûment : « Nosdits sujets n'ont été aucunement convoiez, et neanmoins continuent à payer lesdits vingt sols pour ledit convoi. » Il est dénoncé une " exaction ", une chose " inutile et dommageable ". Sa suppression est décidée par le roi Henri II le 17 janvier 1555 et confirmée le 21 mars 1555. Elle est assortie d'une condition selon laquelle les « habitans se soutiendront comme il l'ont fait par le passé, faisant et donnant telle assurance à ceux qui entreprendront leur navigage, soit pour la négociation ou le fait de la guerre, qu'ils ne se présentent sans quelques asseurances à ce qu'ils ne puissent donner si facilement en proie aux ennemis, et que pareillement quand ils partiront pour le fait de la négociation nos édits soient confirmés ${ }^{137}$ ". À cette date, l'on sait donc que les marchands euxmêmes prenaient à leur charge en commun certains aspects de la sécurité maritime, "négociation [sauf-conduit] ou fait de guerre [convoi] ". Leurs pratiques en la matière étaient désormais reconnues par l'État et devenues obligatoires, ce qui, si l'on suit la documentation disponible ${ }^{138}$, n'était pas

136. LA LANDE DE CALAN, Charles de, Documents inédits relatifs aux États de Bretagne de 1491 à 1589, Nantes, Société des bibliophiles bretons et de l'histoire, 2 vol., 1908, t. I, p. 131 . 2013-05-30T11:02:42

137. Morice, Hyacinthe, Mémoires..., t. III, Col. 1123.

138. Des formes de mutualisation concernant les rapports maritimes des marchands et marins d'un port breton et l'étranger se ne sont pas absentes mais paraissent s'appliquer à d'autres éléments. En atteste la " bourse commune " (sur celle-ci, PLANIOL, Marcel, Histoire des institutions..., op. cit., t. IV, p. 182), système mal renseigné mais attesté au Croisic. Le 5 octobre 1420, au Croisic, entre autres privilèges octroyés aux Croisicais, le duc Jean V leur accorde la possibilité de faire "bourse commune " sur " eulx et leurs biens ", afin de faire " poursuytes de leurs vesseaux, biens et marchandies des lieux ou seront empeschez ", c'est-à-dire d'entamer les procédures nécessaires afin de recouvrer 
avéré auparavant, le convoi ayant empêché la mise en place d'autres stratégies de mutualisation.

Cependant, lors de la session extraordinaire des États de mai 1555, le représentant du roi demande qu'il soit délibéré sur " le nombre des navires qu'il sera besoin armer et équiper pour faire le convoi [et] quels sera requis ". Les États répliquent : " Puis la guerre commencée les marchands de ladite coste se sont équippés et fortiffiés tellement d'artillerie et vaisseaux de guerre pour resister aux entreprises, incursions et assauts des ennemis que maintenant, la grâce à Dieu, ne craignent plus les rencontrer faisant leur route et trafic aux pays étranges. " Pour les États, le convoi est désormais inutile, les marchands assurent leur protection avec des navires d'escorte disposant d'artillerie. Toutefois, le roi entend persévérer dans son projet, deux navires de 100 à 120 tx et quatre galions de 50 tx, une moitié demeurant " deça le Raz ", et l'autre escortant les navires. Les États s'engagent à fournir artillerie, munitions et avitaillement mais " en espèces et non en deniers ". Dans sa réponse délibérée au conseil du roi le 11 juin 1555 , le roi justifie le convoi par l'état de guerre (plus de 200 vaisseaux perdus depuis le début de la guerre). Il prend acte des mesures prises par les marchands, mais impose un convoi composé de deux navires de 150 tx et de quatre galions de 60 à 70 tx, dont le service couvrirait l'année entière et non plus seulement l'été et l'hiver pour le trafic lié aux vins et au pastel de Guyenne : en cela, la mesure évoque plus une flotte militaire affectée à la protection sur une route maritime ${ }^{139}$ qu'un convoi tel qu'il a existé à l'époque ducale. Les États s'inclinent et demandent à nommer ceux qui en auront la charge, que les prises faites par ces navires soient leur propriété et que le droit de 20 sous par tonneau ne soit pas levé sur les marchands commerçant en Normandie ou en Guyenne. Le roi accepte et précise que l'armement des navires est de la responsabilité de l'amiral, mais que les États peuvent présenter les officiers destinés à les commander ${ }^{140}$.

La question du convoi réapparaît à la session extraordinaire des États de novembre 1557. Les États offrent 60000 livres tournois pour l'abolition

le cas échéant navires et biens capturés à l'étranger (BLANCHARD, René, Lettres et mandements..., op. cit., $\mathrm{n}^{\circ}$ 1451). Ce droit leur est confirmé en 1485 (TrAVERs, Nicolas, Histoire civile, politique et religieuse de la ville et du comté de Nantes, 3 vol., Nantes, 1836-1841, t. II, p. 187). Le 15 juillet 1491, soit en plein cœur du conflit franco-breton, le roi Charles VIII confirme, précise et élargit les privilèges du Croisic. Pour la bourse commune, une taxe d'un denier par livre, ad valorem, soit $1 / 240^{\mathrm{e}}$, sera levée sur toutes les marchandises vendues ou déchargées en la paroisse de Batz (dont dépend Le Croisic), et sur celles qui ne font que transiter, sauf sur les blés, le beurre, le lard, les " chairs ", bois et fagots, fèves, poissons frais et vins du " creü " qui seront vendus au détail (Arch. dép. de LoireAtlantique, E, dépôt 38, Le Croisic, AA 2; ibid., 114 J, Le Croisic, 37, f 12-27; ibid., C 704). 139. À rapprocher de cette "force de la mer tant en Normandie, Bretagne que Provence " qui figure à l'état de finances de 1523, et auquel la Bretagne contribue pour 20000 livres tournois sur un total de 50500 livres tournois (DOUCET, Roger, "L'état de finances de 1523 ", Bulletin philologique et historique, Paris, 1922, p. 80).

140. La LANDE DE CALAN, Charles de, Documents inédits relatifs aux États de Bretagne..., op. cit., p. 134-135. 
du droit de convoi, ainsi que 40000 livres tournois pour la suppression des offices de présidents, conseillers, gardes des sceaux créés dans les présidiaux. Par lettres patentes du 20 février 1559, le roi entérine la décision des États ${ }^{141}$. À cette date, le convoi disparaît. Aux yeux des marchands, il ne répond plus à leurs besoins, et il est perçu comme une contrainte à leur commerce et une charge fiscale.

Certes, le système du convoi suscite des oppositions portant sur la fiscalité, son utilisation à des fins militaires par la puissance publique et plus profondément en raison des contraintes de calendrier et des incidences sur le marché qu'elle impose aux marchands et aux transporteurs. Cependant, longtemps, pour les milieux marchands, le convoi se justifie en temps de guerre, la sécurité assurée par les navires d'escorte leur garantissant une sorte de statut de neutralité. Aussi malgré ces réticences, le convoi breton se caractérise-t-il par une grande continuité, puisqu'on peut le suivre de 1372 à 1559. En effet, il est à même de répondre à des intérêts variés : pour les marchands et les transporteurs, en termes de sécurisation et de mutualisation des risques; pour l'État, il concourt au " bien publicque ${ }^{142}$ ", il est l'affirmation d'une fonction régalienne de protection des personnes et de leurs activités, ainsi qu'une source de rentrée d'argent. Mais la longue durée du convoi breton (jusqu'à la fin du règne des Montfort et au-delà), qui ne survit que peu de temps à la réunion des couronnes de France et de Bretagne sur une même tête (en $1547^{143}$ ), appelle d'autres explications. Elle traduit la volonté du pouvoir ducal d'être présent sur un territoire maritime où se trouve une route commerciale internationale, dont les limites dépassent celle du duché au sud, d'affirmer ainsi sa présence sur une sorte de " marche " et d'y imposer ses décisions à ses ressortissants, leur assurant avec une certaine sécurité, une sorte de statut de neutralité ${ }^{144}$.

Il n'en est plus de même dans les années 1550. Dans une Bretagne, où désormais la couronne ducale est réunie à la couronne de France, le convoi devient une simple taxe levée alors qu'il n'y a plus de convoiement; au mieux il concourt à la mise en place d'une force navale mobilisée pour l'année au service du roi, ce que refusent les milieux maritimes. À cette date, ceux-ci ont développé d'autres formes de sécurisation et de mutualisation pour le transport maritime : le convoi breton est condamné, il disparaît définitivement en 1559.

141. Arch. dép. d'Ille-et-Vilaine, C 2877. La LANDE DE CALAN, Charles de, Documents inédits relatifs aux États de Bretagne..., op. cit., p. 139 et p. 141.

142. Arch. dép. de Loire-Atlantique, E 127/10, 31 août 1470.

143. Le PAGE, Dominique et NASSIET, Michel, L'Union de la Bretagne à la France..., op. cit., p. 153-174.

144. CASSARD, Jean-Christophe, "Frontière de mer et marine ducale : l'exemple breton, fin du XV et début XVI ${ }^{\mathrm{e}}$ siècle ", dans BoIs, Jean-Pierre (dir.), Défense des côtes et cartographie historique..., op. cit., p. 41. 


\section{Annexe 1 - Navires et effectifs affectés au convoi}

- $1457: 1000$ combattants sont mobilisés ${ }^{145}$.

- 1459-1460 : 4 flottes avec respectivement, 800, 500, 400, 150 combat$\operatorname{tants}^{146}$.

- 1460-1461 : le convoi est attesté, 2 navires du Croisic participent à la deuxième flotte ${ }^{147}$.

- 1462-1463 : 3 flottes avec respectivement 500, 400 (dont 140 affectés $\mathrm{au}$ " navire de Saint-Malo et des autres havres jusques à Bréhat ") et 300 combattants $^{148}$.

- 1464-1465 : 3 flottes avec respectivement 650 combattants en 5 navires (dont la carraque de l'amiral et 2 caravelles), 400 (dont la nef de La Trinité appartenant à l'amiral si elle est alors présente sur les côtes bretonnes, sinon " ung autre le plus gros navire que on y pourra trouver ") et 300 combattants ${ }^{149}$.

- 1473 : pour la première flotte, 400 combattants et 4 navires, dont l'un est la nef de «feu seigneur du Quelenec " d'un port de $300 \mathrm{tx}$, deux caravelles de 80 à 100 tx chacune et un navire de $50 \mathrm{tx}^{150}$.

$-1481^{151}$

\section{Première flotte}

\begin{tabular}{|c|c|c|c|c|c|}
\hline $\begin{array}{l}\text { navire, nom } \\
\text { et type }\end{array}$ & propriétaire & capitaine & tonnage & combattants & coût \\
\hline $\begin{array}{c}\text { La Françoise } \\
\text { (nef) }\end{array}$ & & $\begin{array}{c}\text { Bizien } \\
\text { Merien } \\
\text { (Morlaix) }\end{array}$ & $250 \mathrm{tx}$ & 120 & $1280 \mathrm{l}$. \\
\hline (barque) & $\begin{array}{l}\text { Alain de La } \\
\text { Motte (vice- } \\
\text { amiral) }\end{array}$ & & & 55 & $500 \mathrm{l}$. \\
\hline $\begin{array}{c}\text { "La grant } \\
\text { neff } "\end{array}$ & $\begin{array}{l}\text { le duc de } \\
\text { Bretagne }\end{array}$ & $\begin{array}{l}\text { Alain de La } \\
\text { Motte }\end{array}$ & & 200 & $224 \mathrm{l} .15 \mathrm{~s}$ \\
\hline (nef) & $\begin{array}{c}\text { Pierre } \\
\text { Landais }\end{array}$ & & $240 \mathrm{tx}$ & 150 & \\
\hline (baleinier) & $\begin{array}{c}\text { Pierre } \\
\text { Landais }\end{array}$ & & $10 \mathrm{tx}$ & 30 & $1450 \mathrm{l}$. \\
\hline total : 5 & & & & 555 & $3454 \mathrm{l} .15 \mathrm{~s}$. \\
\hline
\end{tabular}

145. MoRICE, Hyacinthe, Mémoires..., op. cit., t. II, col. 1717.

146. Arch. dép. de Loire-Atlantique, E 131, f $\mathrm{f}^{\circ} 24 \mathrm{v}^{\circ}, 10$ juillet 1459 ; indiqué à tort pour 1469 par LA NICOLLIÈRE-TEIJERO, " La marine bretonne... ", op. cit., p. 413.

147. Arch. dép. de Loire-Atlantique, $B 2, \mathrm{f}^{\circ} 16 \mathrm{v}^{\circ}$.

148. Arch. dép. de Loire-Atlantique, B $2, \mathrm{f}^{\circ} 91 \mathrm{v}^{\circ}-92$.

149. Arch. dép. de Loire-Atlantique, B 3, 96-96 vº.

150. Arch. dép. de Loire-Atlantique, B $7, \mathrm{f}^{\circ} 120 \mathrm{v}^{\circ}$.

151. Arch. dép. de Loire-Atlantique, E 212/15. 
Seconde flotte : 3000 l. lui sont assignées.

- 1483-1484 : Première flotte (1483) ${ }^{152}$

\begin{tabular}{|c|c|c|c|c|c|}
\hline navire, nom et type & propriétaire & capitaine & tonnage & $\begin{array}{l}\text { combat- } \\
\text { tants }\end{array}$ & coût \\
\hline $\begin{array}{c}\text { "Le Leon" (Lyon) } \\
\text { (nef) }\end{array}$ & amiral & $\begin{array}{l}\text { Jacob du } \\
\text { Parc }\end{array}$ & $200 \mathrm{tx}$ & 120 & 18161. \\
\hline $\begin{array}{l}\text { pinasse de Saint- } \\
\text { Malo }\end{array}$ & & & $40 \mathrm{tx}$ & 40 & $573 \mathrm{l} .6 \mathrm{~s}$. \\
\hline barque & $\begin{array}{c}\text { Alain de La Motte } \\
\text { vice-amiral }\end{array}$ & $\begin{array}{c}\text { Jean Le } \\
\text { Barbu }\end{array}$ & $60 \mathrm{tx}$ & 60 & $824 \mathrm{l}$. \\
\hline $\begin{array}{c}\text { La Marguerite de } \\
\text { Brest (nef) }\end{array}$ & Derien Le Du (Brest) & & $160 \mathrm{tx}$ & 99 & $1507 \mathrm{l} .12 \mathrm{~s}$. \\
\hline $\begin{array}{l}\text { La Michelle d'Auray } \\
\text { (nef) }\end{array}$ & Jean Péro (Auray) & & $90 \mathrm{tx}$ & 75 & $1201 \mathrm{l} .5 \mathrm{~s}$. \\
\hline $\begin{array}{c}\text { La Marie d'Auray } \\
\text { (nef) }\end{array}$ & $\begin{array}{l}\text { Geoffroy Estrillat } \\
\text { (Auray) }\end{array}$ & & $90 \mathrm{tx}$ & 69 & 852 l. $10 \mathrm{~s}$. \\
\hline $\begin{array}{l}\text { La Trésorière de } \\
\text { Saint-Malo (nef) }\end{array}$ & $\begin{array}{l}\text { Pierre Landais } \\
\text { (Saint-Malo) }\end{array}$ & $\begin{array}{c}\text { Louis } \\
\text { Berthelot }\end{array}$ & $80 \mathrm{tx}$ & 50 & $256 \mathrm{l}$. \\
\hline total : 7 & & & $720 \mathrm{tx}$ & 513 & $\begin{array}{c}7030 \mathrm{l} . \\
13 \mathrm{~s} .\end{array}$ \\
\hline
\end{tabular}

Seconde flotte (1483-1484) ${ }^{153}$

\begin{tabular}{|c|c|c|c|c|c|}
\hline navire, nom et type & $\begin{array}{c}\text { proprié- } \\
\text { taire }\end{array}$ & capitaine & tonnage & $\begin{array}{c}\text { combat- } \\
\text { tants }\end{array}$ & coût \\
\hline $\begin{array}{c}\text { "Le grant Lyon" } \\
\text { "La grant nef") }\end{array}$ & amiral & $\begin{array}{c}\text { Yvon } \\
\text { Kerbescat }\end{array}$ & $300 \mathrm{tx}$ & 197 & $\begin{array}{c}1447 \mathrm{l} . \\
10 \mathrm{~s} .\end{array}$ \\
\hline "Le petit Lyon" & amiral & $\begin{array}{c}\text { Jacob du } \\
\text { Parc }\end{array}$ & $180 \mathrm{tx}$ & 120 & $864 \mathrm{l}$. \\
\hline La nef de Morlaix & $\begin{array}{c}\text { Jean } \\
\text { Fleuriot }\end{array}$ & $250 \mathrm{tx}$ & 140 & $\begin{array}{c}2051 \mathrm{l} . \\
10 \mathrm{~s} .\end{array}$ \\
\hline "La Crullier "(Saint- \\
Pol) & & $\begin{array}{c}\text { Jean } \\
\text { Lehen }\end{array}$ & $250 \mathrm{tx}$ & 160 & $\begin{array}{c}1159 \mathrm{l} . \\
10 \mathrm{~s} .\end{array}$ \\
\hline $\begin{array}{c}\text { Le David } \\
\text { La Marguerite (Brest) }\end{array}$ & & $\begin{array}{c}\text { André } \\
\text { Théaaut }\end{array}$ & $160 \mathrm{tx}$ & 120 & $843 \mathrm{l}$. \\
\hline total : 6 & & $1390 \mathrm{tx}$ & 887 & $8465 \mathrm{l}$. \\
\hline
\end{tabular}

152. Arch. dép. de Loire-Atlantique, E 212/18.

153. Arch. dép. de Loire-Atlantique, E 212/18, f ${ }^{\circ}$ 18-21. 
- En 1487 : le 10 janvier, pour la seconde flotte du convoi de 1486-1487, 400 hommes et 3 navires appartenant à l'amiral ${ }^{154}$.

\begin{tabular}{|c|c|c|c|}
\hline navire, nom et type & propriétaire & capitaine & tonnage \\
\hline Le Grand Lion (nef) & amiral & Bizien de Kerrousy & $300 \mathrm{tx}$ \\
\hline Le Petit Lion & amiral & $\begin{array}{c}\text { Olivier, bâtard de } \\
\text { Quelenec }\end{array}$ & $300 \mathrm{tx}$ \\
\hline $\begin{array}{c}\text { La Bonnaventure } \\
\text { (barque) }\end{array}$ & & Denis Coëtedrez & $80 \mathrm{tx}$ \\
\hline total : 3 & & & $680 \mathrm{tx}$ \\
\hline
\end{tabular}

- 1490 : 3 flottes avec respectivement 1000, 600, 400 hommes $^{155}$.

- 1503 : Première flotte ${ }^{156}$

\begin{tabular}{|c|c|c|}
\hline navire, nom et type & propriétaire & équipage \\
\hline $\begin{array}{c}\text { "La grant neff " avec sa « barcque } \\
\text { neuve " }\end{array}$ & sr de La Bouvardière & 300 \\
\hline "La grant nef» de Saint-Malo & & 150 \\
\hline (nef) & sr de Guémadeuc & 60 \\
\hline La nef de Lantriguier & & 70 \\
\hline $\begin{array}{c}\text { (4 navires du " capitaine " } \\
\text { Portzmoguer " o sa bande ") }\end{array}$ & & 300 ("par estime") \\
\hline "L'Espaigneul» de Quimper & & 70 \\
\hline "La grant nef" & Guillaume Finamour & 100 \\
\hline "le navire de Jean Frolai " & & 80 \\
\hline La nef de Vannes & & 120 \\
\hline La Michelle du Croisic & & 140 \\
\hline "Le Senechal" & & \multirow[t]{2}{*}{300} \\
\hline "Le Chappon" & & \\
\hline $\begin{array}{l}+ \text { navire « recoupvré " par } \\
\text { Portzmoguer }(300 \text { tx })\end{array}$ & Portzmoguer & 200 \\
\hline total : 17 & & environ 1890 \\
\hline
\end{tabular}

154. Arch. dép. de Loire-Atlantique, B 10, f 111 v ${ }^{\circ} 112$; Morice, Hyacinthe, Mémoires..., op. cit., t. III, col. 535 .

155. Arch. dép. de Loire-Atlantique, B 12, f $185 \mathrm{v}^{\circ}$ et ibid., B 13, $\mathrm{f}^{\circ} 4$, septembre 1490.

156. Arch. dép. de Loire-Atlantique, $B$ 14, $f^{\circ}$ 107-108. Peu après le 19 septembre, La Catherine de Loctudy remplace la nef de Guillaume Finamour $\left(\mathrm{f}^{\circ} 118 \mathrm{v}^{\circ}\right)$. 
Figure 1 - Le convoi à la fin $\mathrm{du}_{\mathrm{X}} \boldsymbol{v}^{e}$ siècle

(Source : Kerhervé, Jean, L'État breton aux $14^{\mathrm{e}}$ et $15^{\mathrm{e}}$ siècles. Les ducs, l'argent et les hommes, Paris, Maloine, 1987, t. II, p. 685)

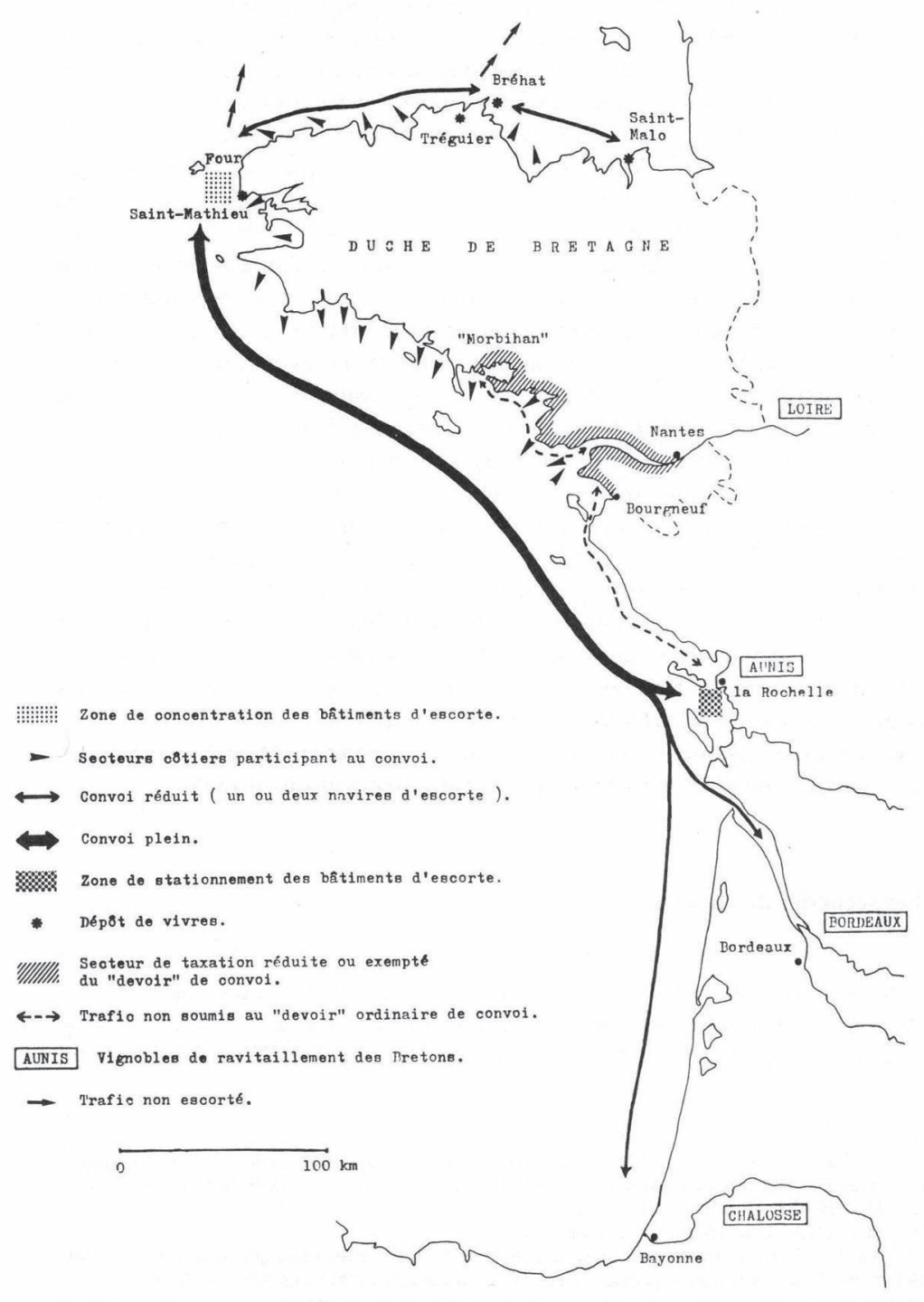


Figure 2 - Les ports bretons au $X V^{e}$ siècle où étaient perçus les devoirs d'“ entree et d'yssue »

(Source : Kerhervé, Jean, L'État breton aux $14^{\mathrm{e}}$ et $15^{\mathrm{e}}$ siècles..., op. cit., t. I, p. 110)

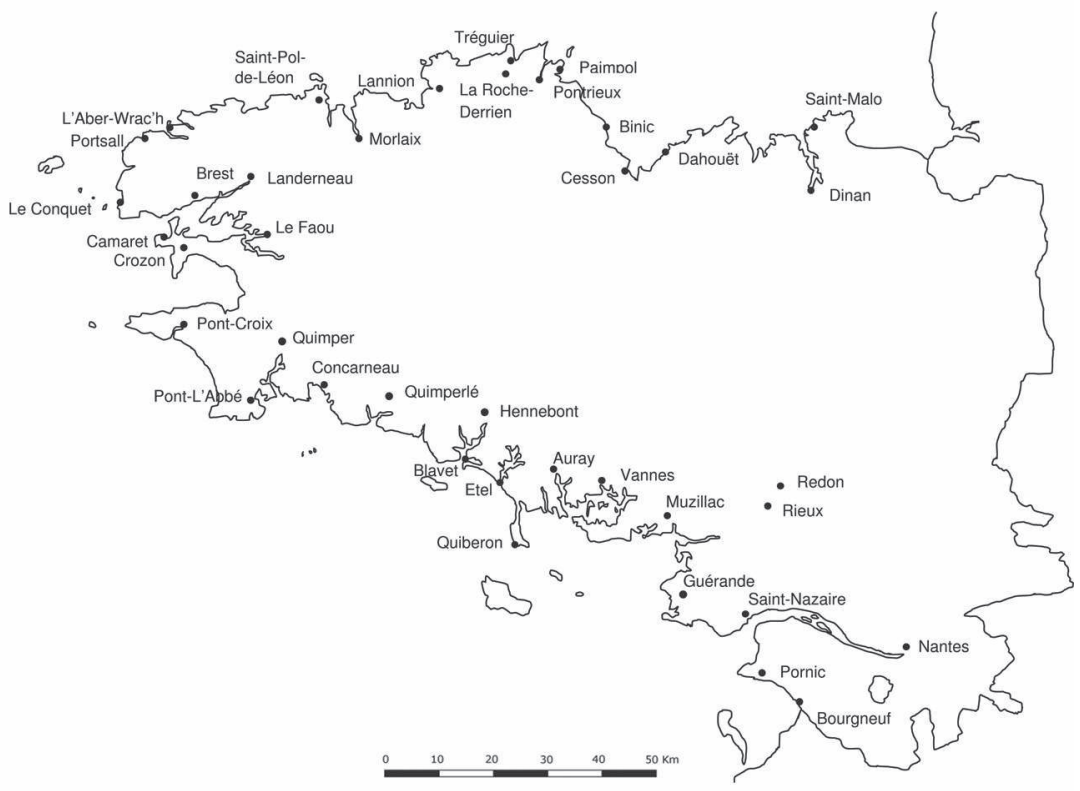




\section{RÉSUMÉ}

L'originalité du convoi breton, institué en 1372, répond à la fois à un problème d'insécurité publique et à des préoccupations économiques et fiscales. La souplesse de l'organisation lui permet de s'adapter rapidement aux réalités commerciales et politiques. À l'origine, il s'agit d'une stratégie de lutte contre le risque de piraterie, voulue par les marchands eux-mêmes, mais le convoi devient de plus en plus contraignant avec une fiscalisation accrue, inhérente à la politique d'affirmation princière menée par la dynastie Montfort dans le duché. S'il survit à la réunion de la Bretagne à la France, le système suscite de plus en plus d'oppositions qui conduisent à sa suppression en 1559 .

\section{ABSTRACT}

The specificity of the Breton sea convoy, instituted in 1372, was a result of the problem of public safety and of financial and economic fears. The organisation's flexibility allowed it to cope rapidly with changing commercial and political realities. Originally, it was a way to fight against the risk of piracy and was requested by the merchants themselves. But the convoy became increasingly restrictive with a more burdensome taxation - a consequence of the assertion of princely power by the Montfort dynasty. Even though it outlasted the reunification of Brittany with France, the system met with increasingly opposition, which eventually led to its abolition in 1559 . 